\title{
Quality Differentiation of Durable Goods in Secondary Markets*
}

\author{
Richard Saito* $^{* *}$
}

Summary: 1. Introduction; 2. Description of the durable market; 3. A model of endogenous quality differentiation; 4. Conclusions.

Keywords: durable goods; quality differentiation; secondary markets.

JEL codes: D43; D62 ; D82.

This paper presents a framework to study how changes in exogenous parameters, such as quality levels of new and used durables, affect the composition of durable good stocks. Our model extends the previous literature by including the endogeneity of prices and qualities. Our results could be applied to evaluate policies for controlling the externality level associated with the use and quality of durable goods in the long-term. We studied the characterization of the demand under a special situation: the consumer can choose the operation and/or maintenance level in the period the durable goods are new, which determines the quality levels for the subsequent periods. Comparative statics is performed to analyze the effects of exogenous variable change on the composition of durable stocks, and thus its impact on the externality level associated with each quality level. Contrary to most expectations, we provide an example in which the regulator imposes stricter quality standards for new durables to decrease negative externality associated with the use of durables. In this example, the comparative static results show that policies focusing only on new durable externality control may turn out to increase total externality, since stocks of older vintages may increase.

Este trabalho apresenta uma estrutura para analisar as mudanças de parâmetros exógenos, tais como níveis de qualidade de bens duráveis novos e usados sobre a composição de estoques de bens duráveis. O modelo amplia a literatura anterior ao incluir a endogeneidade de preço e qualidade. Os resultados podem ser aplicados para avaliar políticas destinadas a controlar o nível de externalidade associado ao uso e à qualidade de bens duráveis a longo prazo. Para analisar o impacto desses programas regulamentares, é impor-

${ }^{*}$ This paper was received in April 2001 and approved in June 2002.

** Professor, Escola de Administraçao de Empresas de São Paulo / Fundação Getulio Vargas. 
tante estudar as mudanças associadas na composição de estoques de bens duráveis. O artigo avalia a caracterização da demanda sob uma situação especial: o consumidor pode escolher o nível de operação e/ou manutenção no período em que os bens duráveis são novos - que determina os níveis de qualidade para os períodos subseqüentes. Estática comparativa é utilizada para observar os efeitos de mudança variável exógena na composição de estoques de duráveis, e, conseqüentemente, seu impacto no nível de externalidade associado a cada nível de qualidade. Contrariamente à maioria das expectativas, os resultados da análise mostram que políticas voltadas apenas para o controle de externalidade de duráveis novos podem acabar aumentando a externalidade total, uma vez que estoques de bens duráveis mais usados podem aumentar.

\section{Introduction}

In some durable good markets there is a substantial trade in secondary markets. The explanation for the magnitude of these trades is the quality differentiation, which occurs in secondary markets as durable goods deteriorate, as well as the heterogeneity of the consumer population with respect to the taste for quality (or income/wealth differences). If all consumers were identical in terms of quality preference, the prices of used durable goods would adjust to have the same prices of services from new and used durable goods, including all incurred costs to operate/use a durable good of a certain physical condition. In this case, trades would not occur in the presence of transaction costs or information asymmetries. On the other hand, if consumers were heterogeneous, then secondary markets would exist, since there would be a potential gain by trading durable goods in different conditions (e.g., qualities); and barriers like transaction costs and information asymmetries would be overcome.

A typical example is the used car market. According to Berkovec (1985)'s survey on new car buyers, $80 \%$ of new car purchases replace previous cars. In addition, $55 \%$ of new car buyers plan to keep their cars for at most five years, while the median lifetime is about eight years. These figures show that there might be substantial gains by trading used durables. Other examples of secondary markets include a wide range of durables such as ships, trucks, farm and factory equipment, and housing.

Previous works have focused on quality differentiation offered by the producer (see for example Deneckere and de Palma (1988), Hamilton and Burke (1996)). They do not take into account the quality differentiation in secondary markets. 
However, there is a broad literature on the economics of durable goods which provides the theory to explain trading among consumers, as well as other aspects such as quality interdependence among prices, quantities, rates of deterioration, durability maintenance and operation expenses ${ }^{1}$ By understanding how consumers trade in secondary markets, one can understand how policy actions to regulate externality from a durable class may affect consumers' decision and, thus, changes in demands for each durable quality.

The general framework for analyzing durable goods markets has often incorporated the following assumptions: 1 . The lifetime distribution of a durable is determined at the time of manufacture, 2. New and used durables are perfect substitutes, 3. A complete, competitive rental market exists. This framework is known as the "user cost" model due to Rust (1985). Chow (1957) and Parks (1977) have performed and confirmed empirically the "substitution hypothesis" for the automobile market. However, this model is limited, since it does not allow quality differentiation in secondary markets, i.e., new and used durables are considered perfect substitutes.

Berkovec (1985) and Bond (1983) have introduced the idea that new and used durables are not perfect substitutes. Bond examines the pattern of trade in used asset markets where firms have different factor prices and utilization rates of capital. He shows that with heterogeneous firms, the price of used machines will reflect the characteristics of firms as well as the productivity of used machines. Berkovec uses a theoretical model, which allows an unlimited degree of heterogeneity of both consumers and products. His model combines a discrete choice model of consumer automobile demand with simple models of new automobile production and used vehicle scrappage. However, because the model is designed for numerical computation, it is difficult to characterize the basic properties of equilibrium in this framework.

Besides the difficulties in building a model of differentiation in secondary markets, there is also a strong intertemporal linkage of prices of used durables. The solution technique for this problem should solve an equilibrium price path. To simplify this problem, Rust (1985) studied stationary equilibrium in a market for durables. Stationary equilibrium allows a strong simplification, since the equilibrium price path is not considered for analysis, and at the same time it allows the characterization of the demand side.

\footnotetext{
${ }^{1}$ See for example Purohit (1992), where a model is developed to explore the relationship between primary markets for new cars and secondary markets for used cars. In particular, he analyses how prices of older versions in the secondary market adjust in response to changes incorporated in new versions of the product.
} 
To characterize the basic properties of equilibrium in a market of durable goods, one needs a notion of quality hierarchy to rank durable qualities. The commodity hierarchy framework was developed by Sweeney (1974) to analyze the dynamics of the housing market. In his framework, the durable good passes through successive levels of the hierarchy as it ages and the good at each level is an imperfect substitute for all goods at other levels. The hierarchy is characterized by mutual exclusivity and equal partial ranking by all consumers. Under this structure of quality ranking, he derived some properties of individual and market demand functions for commodities of different qualities as well as comparative price changes in response to supply changes at one or more levels.

Information on quality of used durables sometimes plays an important role in determining the basic characteristics of equilibrium in secondary markets. This happens when one does not have perfect information on the quality of used durables. Kim (1985) uses a model in which quality differentiation is endogenously determined to show how consumer information may exist and even so there are markets for used and new durables.

The purpose of this paper is to present a framework to study how changes in exogenous parameters, such as quality levels of new and used durables, affect the composition of durable good stocks. Our model extends the previous literature by including the endogeneity of prices and qualities. Endogenous prices are determined to satisfy the stationary equilibrium, given by the condition "supply equals demand" at every quality level. Endogenous qualities play an important role when one does not have sufficient information on the quality of used durables. By using a two-period durable model, we can draw several conclusions on how exogenous factors affect the composition of durable good stocks. These results could be applied to evaluate policies for the control of the externality level associated with the use and quality of durable goods in the long-term. Thus, to analyze the impact of these regulatory programs, it is important to study the associated changes in the composition of durable stocks. ${ }^{2}$

This paper is organized as follows. In section 2, we describe a general market for durable goods, and we derive the optimal conditions for the consumer maximization problem. Section 3 analyzes the effects of endogenous quality differentiation on equilibrium in the used durable market under perfect information and asymmetric information. An example of policy evaluation for externality level control is also provided in section 3. Finally, section 4 summarizes our results.

\footnotetext{
${ }^{2}$ We can show that the demand for durable goods in the case of heterogeneous consumers will be higher than that of homogeneous consumers. This implies a higher externality level associated with the use of these durables. Thus, it is important to analyze the role secondary markets play.
} 


\section{Description of the Durable Market}

We consider a market in which a commodity deteriorates with use (or age). In addition, its physical condition eventually reaches the point where there is no more usage for the purpose it was manufactured or it is not economically feasible to keep the durable any longer. At this point, the durable is scrapped. At the same time, it is common to find owners who decide to trade this durable before the end of its lifetime, since a used good which does not appeal to some customers might appeal to other customers. Thus, we might have a substantial gain just by trading used durables. This implies the existence of a secondary market.

Therefore, we consider that the market for durables consists of three types of agents - producers, consumers, and scrappers - as follows:

- Producers: We assume that there is only one producer in the market, and this producer offers only one quality of good. Its quality (or physical condition) is represented by a nonnegative real number $q_{t}$ at time $t$, which decreases as the durable good deteriorates. In general, durable goods present increasing operating and maintenance costs as their quality deteriorates.

- Consumers: Each consumer has a utility function $U(q ; \theta)$, where $q$ is the product quality, and $\theta>0$ measures the consumer's taste for quality. We shall assume that $U(q ; \theta)$ may be approximated by:

$$
U(q ; \theta)=u(q ; \theta)-c(q)-\Delta P(q)
$$

where $u(q ; \theta)$ is an increasing function in $q$ and $\theta, c(q)$ represents the operating and maintenance costs of the durable quality $q$, and $\Delta P$ is the depreciation cost of the durable quality $q$, i.e., $\Delta P(q)=P(q)-\beta P(q-\delta)$ where $P(q)$ is the price of durable quality $q, q-\delta$ is its new quality level after one time period, and $\beta$ is the discount factor. Consumer's valuation of quality has a distribution whose density $w(\theta)$ is defined on $\Theta \equiv\lfloor\underline{\theta}, \bar{\theta}\rfloor$.

- Scrappers: We assume that the demand for these products which belongs to a certain product class is perfectly elastic. This means that the scrap value is fixed at a certain value $P_{s}$, where $P_{s}$ may represent the value of the material contained in the durable and is assumed to have the same value regardless of the durable quality. 
To complete the description of the durables market, we introduce the following assumptions:

ASSUMPTION 1 There is no transaction cost involved in trading, and all trading occurs at equilibrium prices.

Assumption 2 Each consumer can costlessly identify the quality (physical condition) of the durable, and knows the price structure of secondary markets.

Assumption 3 The supply of new products is perfectly price elastic, i.e., the price of new products is fixed at some value determined by the producer, $P_{n}^{t}$, at every period $t$.

Assumption 4 The demand for scrapped products is also perfectly price elastic so that it is fixed at $P_{s}^{t}$ in every period $t$.

ASSUMPTION 5 We confine our analysis to a stationary equilibrium in which the same pattern of trade continually repeats over periods, and the prices of a given quality level are time invariant. Therefore, we can drop the superscript $t$ for all variables.

Therefore, each consumer buys and sells a used durable at equilibrium prices, and has perfect information on the quality of used durables. In addition, each consumer holds at most one unit per period and chooses an optimal durable selection and replacement policy to maximize the expected utility of owning an infinite sequence of assets. If the consumer chooses not to hold the durable, his utility of consuming the next best substitute (or alternative service) for the durable is $u_{a}(\theta)-A$, where $A \equiv c(a)$ represents the use (or rental) cost and $u_{a}(\theta) \equiv u(a ; \theta)$, i.e., the utility to use the alternative service.

At the beginning of each period, the consumer must choose one of the following alternatives: (a) continue to hold the current durable of quality q; (b) trade the current good of quality $q$ for a durable of quality $z$; (c) exit the market and use the alternative service. At this point, it is convenient to define a new variable, $F(q ; \theta)$ : $F(q ; \theta)=u(q ; \theta)-c(q)-P(q)$, where $F(q ; \theta)$ represents the net utility of owning a durable quality $q$ for one time period, after discounting the capital and operating costs. Its relationship to $U(q ; \theta)$ is as follows: $U(q ; \theta)=F(q ; \theta)+\beta P(q-\delta)$, i.e., $F(q ; \theta)$ does not account for the sale of the durable good after one-period of usage. The one-period utilities, $U(q ; \theta)$, associated with each alternative are: (a) 
$F(q ; \theta)+P(q)+\beta P(q-\delta) ;(\mathrm{b}) F(z ; \theta)+P(q)+\beta P(z-\delta) ;$ and $(\mathrm{c}) F(a ; \theta)+P(q)$.

\section{A Model of Endogenous Quality Differentiation}

Consider that each durable good provides services for exactly two periods: in the first period they are called new $(n)$, and in the second period they are named used durables $(u)$. After the second period, used durables are scrapped at a salvage value equal to $P_{s}$. We assume that the scrappage rate for new durables is zero so that all new durables become used durables after one period of use.

In addition, we include the situation where consumers can choose the maintenance and operation levels. ${ }^{3}$ This implies an endogenous quality differentiation in the secondary market. That is, we will have an array of quality of used durables, which will depend on the maintenance level in the period durables are new. Due to the quality differentiation in the used durable market, the information on the part of potential buyers regarding the quality of used durables plays an important role in determining the new equilibrium. We shall discuss two cases: asymmetric information and perfect information.

\subsection{Asymmetric information}

So far we have not mentioned how maintenance and operation patterns of different consumers influence the quality of durables. In this section, we assume that consumers can choose the level of maintenance for new durables so that the qualities of new and used durable goods are functions of the maintenance and operation level that consumers choose during the period that goods are new. This implies that the quality of used durables varies over a range of values rather than being limited to a specific value.

We follow closely Kim's work (1985) to include the quality of used durables as endogenous variable into our model. Basically, we assume: 1) quality of a durable is endogenous, varying with a level of maintenance; and 2) quality of used durables is determined by previous period maintenance level. We extend his model to include comparative statics and perfect information under our two-period durable good hierarchy structure.

The quality of a new product is a continuously differentiable, increasing and strictly concave function of the maintenance level, $m: q_{n}(m)$ with $q_{n}^{\prime}>0$ and

\footnotetext{
${ }^{3}$ We can assume that a higher maintenance level is required to operate a durable good at a higher level. For instance, a car which is driven more may require more maintenance. Thus, we can implicitly use the term maintenance level to include the operation level as well.
} 
$q_{n}^{\prime \prime}<0$ : it increases as the maintenance level $m$ increases, but at a decreasing rate. The quality of used products is assumed to be a function of the level of maintenance determined in the previous period, when the product was new. We define $q_{u}(m)$ as the quality of a good for the second period, where $m$ is determined in the previous period: $q_{u}^{\prime}>0$ and $q_{u}^{\prime \prime}<0 .{ }^{4}$ Moreover, we make the following assumptions:

Assumption 6 The quality level of a new product is always superior to the quality level of a used product, regardless of the level of operation and maintenance chosen in the first period, i.e., $q_{u}(\infty)<q_{n}(0)$.

Assumption 7 We assume that there is no information availability to the buyers of a used good (e.g. signaling, or warranty). As a result, buyers of used goods make their decisions on the average quality of used cars, and there is only one equilibrium price, $P_{u}$, at which all transactions occur.

The options are the same as defined in the last section: starting from the state of owning no durable, a type- $\theta$ consumer faces four options: 1 ) buy a new product, and in the second period sell it and buy again a new one; 2) buy a new product and keep it for both periods; 3 ) buy a used product, scrap it at the end of the first period, and repeat the same procedure in the second period; and 4) do not buy any good. The corresponding two-period utilities for option $i$ are:

$$
\begin{gathered}
U_{1}(\theta)=(1+\beta)\left[-P_{n}+\beta P_{u}+\theta q_{n}\left(m_{1}(\theta)\right)-m_{1}(\theta)\right] \\
U_{2}(\theta)=-P_{n}+\beta^{2} P_{s}+\theta q_{n}\left(m_{2}(\theta)\right)+\beta \theta q_{u}\left(m_{2}(\theta)\right)-m_{2}(\theta) \\
U_{3}(\theta)=(1+\beta)\left[-P_{u}+\beta P_{s}+\theta q_{u}^{e}\right] \\
U_{4}(\theta)=0
\end{gathered}
$$

\footnotetext{
${ }^{4}$ Note that maintenance only occurs when the product is new and determines the entire future of quality. This assumption is used to see the effects of asymmetric information on the market for used durables. We could have included a second parameter in the quality function maintenance of used durables to represent the maintenance level of used durables, i.e., $q_{u} \equiv q_{u}\left(m_{n}, m_{u}\right)$, where $m_{n}$ is the maintenance level in the first period and $m_{u}$ is the maintenance level in the second period. However, we shall assume that: $\frac{\partial q_{u}}{\partial m_{n}}>>\frac{\partial q_{u}}{\partial m_{u}}$ and, thus, it is appropriate to neglect $\frac{\partial q_{u}}{\partial m_{u}}$ and its effects.
} 
where $q_{u}^{e}$ is the expected average quality of traded used durables. We explain our definition of equilibrium in the secondary market as follows:

DeFINITION 1 The secondary durable good market for a two-period durable good is in (stationary) equilibrium, given $P_{n}$ and $P_{s}$, if there exists $P_{u}$ such that:

$$
\begin{gathered}
D_{1}=D_{3} \\
q_{u}^{e}=\int_{T_{1}} q_{u}\left(m_{1}(\theta)\right) w(\theta) d \theta / W\left(T_{1}\right)
\end{gathered}
$$

and $D_{1}$ and $D_{3}$ are the demands for options 1 and 3, respectively, i.e., the demand for new durable goods and the demand for used durables. $T_{\alpha}$ is the set of consumers who choose option $\alpha ; \alpha=1,2,3,4$.

Condition (1) is the market-clearing condition for the used durable market. Condition (2) says that the consumers' expectations about the average quality of traded durables is correct.

Consumers in sets $T_{1}$ and $T_{2}$ choose their maintenance levels to maximize their utilities. Assuming interior solutions, $m_{1}(\theta)$ and $m_{2}(\theta)$ satisfy $\theta q_{n}^{\prime}\left(m_{1}\right)=1$ and $\theta q_{n}^{\prime}\left(m_{2}\right)+\theta \beta q_{u}^{\prime}\left(m_{2}\right)=1$, respectively. The nature of equilibrium depends on the shapes of the $U_{i}$ 's:

$$
\begin{gathered}
U_{1}^{\prime}=(1+\beta) q_{n}\left(m_{1}(\theta)\right) \\
U_{2}^{\prime}=q_{n}\left(m_{2}(\theta)\right)+\beta q_{u}\left(m_{2}(\theta)\right) \\
U_{3}^{\prime}=(1+\beta) q_{u}^{e} \\
U_{4}^{\prime}=0
\end{gathered}
$$

Note that $U_{1}, U_{2}$, and $U_{3}$ are increasing functions of $\theta$. Moreover, we note that $q_{n}\left(m_{2}(\theta)\right)>q_{n}\left(m_{1}(\theta)\right)$ for a given $\theta$. That is, consumers who keep the durable for the entire life, maintain it better (or use it less), if trades were not allowed. In addition, see that $U_{1}$ is steeper than $U_{3}, q_{n}(0)>q_{u}(\infty)$. However, we cannot say whether or not $U_{2}$ is steeper than $U_{1}$ and $U_{3}$, for the reason pointed out before. We consider two cases of interest: 1) $U_{1}^{\prime}>U_{2}^{\prime}>U_{3}^{\prime}$; and 2) $U_{2}^{\prime}>U_{1}^{\prime}>U_{3}^{\prime}$. In 
what follows we make an equilibrium analysis of the two cases of interest.

Case 1: $U_{1}^{\prime}>U_{2}^{\prime}>U_{3}^{\prime}$

A possible equilibrium situation is shown in figure 1 . We define $\theta_{1}$ as the marginal consumer who is indifferent between options 1 and 2. Likewise, $\theta_{2}$ and $\theta_{3}$ are the marginal consumers who are indifferent between options 2 and 3 , and options 3 and 4 , respectively. The sets $T_{i}$ 's, which are assumed to be nonempty, are defined as follows:

$$
\begin{array}{ll}
T_{1}=\left[\theta_{1}, \bar{\theta}\right] & T_{2}=\left[\theta_{2}, \theta_{1}\right) \\
T_{3}=\left[\theta_{3}, \theta_{2}\right) & T_{4}=\left[\underline{\theta}, \theta_{3}\right)
\end{array}
$$

The definitions above together with the utility functions for each option lead to the following values for $\theta$ 's:

$$
\begin{gathered}
\theta_{1}=\frac{\beta P_{n}-(1+\beta) \beta P_{u}+\beta^{2} P_{s}+(1+\beta) m_{1}-m_{2}}{(1+\beta) q_{n}\left(m_{1}\right)-q_{n}\left(m_{2}\right)-\beta q_{u}\left(m_{2}\right)} \\
\theta_{2}=\frac{P_{n}-(1+\beta) P_{u}+\beta P_{s}+m_{2}}{q_{n}\left(m_{2}\right)+\beta q_{u}\left(m_{2}\right)-(1+\beta) q_{u}^{e}} \\
\theta_{3}=\frac{P_{u}-\beta P_{s}}{q_{u}^{e}}
\end{gathered}
$$

We note that agents with higher preferences $\left(T_{1}\right.$ and $\left.T_{2}\right)$ for durable quality buy new durables and consumers with lower preferences $\left(T_{3}\right)$ buy used ones. Because of the steepness condition, agents with higher preferences $\left(T_{1}\right)$ sell their durables at the end of the first period of use, while intermediate preference consumers $\left(T_{2}\right)$ keep their products for the whole lifetime. 
Figure 1

Case 1: $U_{1}^{\prime}>U_{2}^{\prime}$

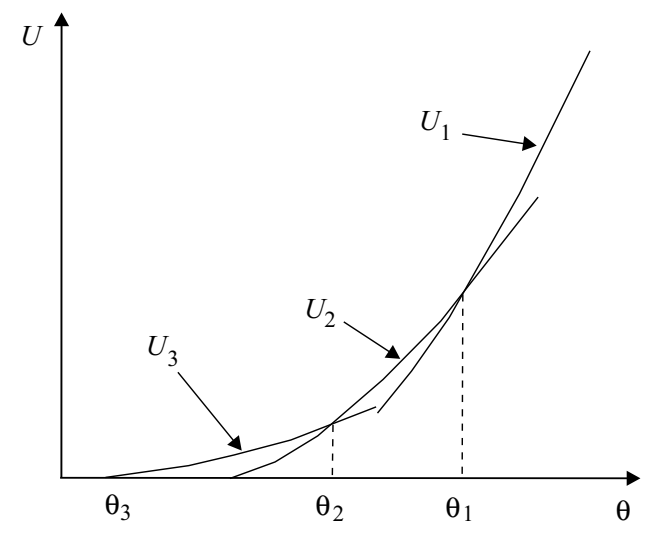

Note also that consumers in $T_{1}$ select higher maintenance levels than those of consumers in $T_{2}$. This might imply a higher average quality of traded durables than of nontraded durables (in $T_{2}$ ). On the other hand, consumers who keep durables for two periods maintain them better for a given $\theta$, so that there are two opposite forces. The following numerical example illustrates how we might have the two results stated in the last paragraph, depending on the quality functions.

NUMERICAL EXAMPLE 1: Suppose that

$$
\begin{aligned}
& q_{n}^{1}(m)=2-2 \exp (-m / 2) \\
& q_{u}(m)=(1-\exp ((-m / 2)) / 2 \\
& q_{n}^{2}(m)=2-3 / 2 \exp (-m)
\end{aligned}
$$

where $\theta$ is distributed uniformly on $[7,8]$, i.e., $w(\theta)=1 \forall \theta \in[7,8]$. We assume that $P_{n}=13, P_{s}=1, \beta=0.95$, and we consider two cases: (a) the quality function $q_{n}^{1}$, and (b) the quality function $q_{n}^{2}$. For case (a), the average quality of nontraded durables is 0.448 , while that of traded durables is 0.436 . However, for case (b), the quality of nontraded durables (0.387) is lower than that of traded durables (0.427). Thus, case (a) presents an average quality of nontraded durables higher than that of traded durables, while case (b) shows the contrary. 
Let us briefly analyze the impact of changing the price of new durables and the scrap value. First, an increase in the price of new durables leads to the following inequalities: ${ }^{5}$

$$
\begin{gathered}
\frac{\partial \theta_{1}}{\partial P_{n}}=\frac{1}{\Delta q_{1}}\left[\beta-(1+\beta) \beta \frac{\partial P_{u}}{\partial P_{n}}\right]>0 \\
\frac{\partial \theta_{2}}{\partial P_{n}}=\frac{1}{\Delta q_{2}}\left[1-(1+\beta) \frac{\partial P_{u}}{\partial P_{n}}\right]>0 \\
\frac{\partial \theta_{1}}{\partial P_{n}}=\frac{1}{\Delta q_{3}} \frac{\partial P_{u}}{\partial P_{n}}>0
\end{gathered}
$$

where $\Delta q_{1}=(1+\beta) q_{n}\left(m_{1}\right)-q_{n}\left(m_{2}\right)-\beta q_{u}\left(m_{2}\right), \Delta q_{2}=q_{n}\left(m_{2}\right)+\beta q_{u}\left(m_{2}\right)-(1+\beta) q_{u}^{e}$ and $\Delta q_{3}=q_{u}^{e}$ are the quality differences between two successive levels. We could easily we know that $0<\frac{\partial P_{u}}{\partial P_{n}}<\frac{1}{1+\beta}<1$.

Therefore, as the price of new durables increases, the supply of and demand for used durables decrease. This implies a higher average quality of new durables as well as a higher average quality of used durables. The change in demand for new durables which are kept for their entire life is:

$$
\frac{\partial D_{2}}{\partial P_{n}}=w\left(\theta_{1}\right) \frac{\partial \theta_{1}}{\partial P_{n}}-w\left(\theta_{2}\right) \frac{\partial \theta_{2}}{\partial P_{n}}
$$

or

$$
\frac{\partial D_{2}}{\partial P_{n}}=\left[\beta \frac{w\left(\theta_{1}\right)}{\Delta q_{1}}-\frac{w\left(\theta_{2}\right)}{\Delta q_{2}}\right]\left[1-(1+\beta) \frac{\partial P_{u}}{\partial P_{n}}\right]
$$

Thus, the demand for $D_{2}$ will increase if $\left(w\left(\theta_{2}\right) \Delta q_{1}\right) /\left(w\left(\theta_{1}\right) \Delta q_{2}\right)<\beta$. Otherwise, the demand $D_{2}$ will decrease.

Now, let us investigate the case of an increase in the scrap value. As before, the changes in the marginal consumers are:

\footnotetext{
${ }^{5}$ We have implicitly assumed that changes in the average quality of used durables may be neglected. In fact, this is reasonable for small changes in $P_{s}$ and $P_{n}$.
} 


$$
\begin{aligned}
\frac{\partial \theta_{1}}{\partial P_{s}} & =\frac{1}{\Delta q_{1}} \beta\left[\beta-(1+\beta) \frac{\partial P_{u}}{\partial P_{s}}\right]<0 \\
\frac{\partial \theta_{2}}{\partial P_{s}} & =\frac{1}{\Delta q_{2}}\left[\beta-(1+\beta) \frac{\partial P_{u}}{\partial P_{s}}\right]<0 \\
\frac{\partial \theta_{3}}{\partial P_{s}} & =\frac{1}{\Delta q_{3}}\left[\frac{\partial P_{u}}{\partial P_{s}}-\beta\right]<0
\end{aligned}
$$

We can know that $\beta>\frac{\partial P_{u}}{\partial P_{s}}>\frac{\beta}{1+\beta}$. Therefore, as the scrap value increases, the supply of and demand for used durables increase. This implies a lower average quality of new durables. However, the change in demand for new durables which are kept for their entire life is:

$$
\frac{\partial D_{2}}{\partial P_{n}}=w\left(\theta_{1}\right) \frac{\partial \theta_{1}}{\partial P_{s}}-w\left(\theta_{2}\right) \frac{\partial \theta_{2}}{\partial P_{s}}
$$

or

$$
\frac{\partial D_{2}}{\partial P_{n}}=\left[\beta \frac{w\left(\theta_{1}\right)}{\Delta q_{1}}-\frac{w\left(\theta_{2}\right)}{\Delta q_{2}}\right]\left[\beta-(1+\beta) \frac{\partial P_{u}}{\partial P_{s}}\right]
$$

Thus, the demand for $D_{2}$ will increase if $\frac{w\left(\theta_{2}\right) \Delta q_{1}}{w\left(\theta_{1}\right) \Delta q_{2}}>\beta$. Otherwise, the demand $D_{2}$ will decrease.

Note that when one increases (decreases) the price of new durables or decreases (increases) the scrap value, we have an increase (decrease) in the depreciation cost. Thus, the demand for and supply of used durables decreases (increases). The demand $D_{2}$ for durables which are kept for the lifetime will change according to the condition on $\left(w\left(\theta_{2}\right) \Delta q_{1}\right) /\left(w\left(\theta_{1}\right) \Delta q_{2}\right)$. If $\left(w\left(\theta_{2}\right) \Delta q_{1}\right) /\left(w\left(\theta_{1}\right) \Delta q_{2}\right)<\beta$, then the demand increases. This is because the additional consumer population who shift from option 1 to option $2, \Delta W_{12}$, is bigger than the additional population who shift from option 2 to $3, \Delta W_{23}$, so that the net population shifting to option 2 is positive, i.e.:

$$
\Delta W_{12}=\beta \frac{w\left(\theta_{1}\right)}{\Delta q_{1}}\left[\beta-(1+\beta) \frac{\partial P_{u}}{\partial V}\right] \Delta V>\frac{w\left(\theta_{2}\right)}{\Delta q_{2}}\left[\beta-(1+\beta) \frac{\partial P_{u}}{\partial V}\right] \Delta V=\Delta W_{23}
$$


Note that $\Delta W_{12}$ is inversely proportional to $\Delta q_{1}$, i.e., more consumers will shift if the quality difference between options 1 and 2 is smaller. A smaller quality difference means that options 2 and 1 are closer to perfect substitutes. The same happens for $\Delta W_{23}$. That is, more consumers will shift to option 3 from 2 , the smaller the quality difference between them is.

Finally, let us investigate the equilibrium in the used durables market. Its demand and supply functions can be expressed as: $S_{u} \equiv \int_{\theta_{1}}^{\bar{\theta}} w(\theta) d \theta, D_{u} \equiv \int_{\theta_{3}}^{\theta_{2}} w(\theta) d \theta$. Then, the partial derivatives with respect to $P_{u}$ :

$$
\frac{\partial S_{u}}{\partial P_{u}}=-w\left(\theta_{1}\right) \frac{\partial \theta_{1}}{\partial P_{u}}, \frac{\partial D_{u}}{\partial P_{u}}=w\left(\theta_{2}\right) \frac{\partial \theta_{2}}{\partial P_{u}}-w\left(\theta_{3}\right) \frac{\partial \theta_{3}}{\partial P_{u}}
$$

Another observation is the fact that an increase in $\theta_{1}$ implies an increase in the average quality of traded durable goods, $q_{u}^{e}$, since those consumers will choose a higher maintenance level. This fact allied to the signs of the partial derivatives as follows: $\frac{\partial \theta_{1}}{\partial P_{u}}<0, \frac{\partial \theta_{2}}{\partial P_{u}}<0, \frac{\partial \theta_{3}}{\partial P_{u}}>0$, which implies: $\frac{\partial S_{u}}{\partial P_{u}}>0, \frac{\partial D_{u}}{\partial P_{u}}<0$.

Case 2: $U_{2}^{\prime}>U_{1}^{\prime}>U_{3}^{\prime}$

We define $\theta_{4}$ as the marginal consumer who is indifferent between options 2 and 1 , and $\theta_{5}$ and $\theta_{6}$ as the marginal consumers who are indifferent between options 1 and 3 , and options 3 and 4 , respectively. Figure 2 illustrates a possible equilibrium situation where $T_{1}=\left[\theta_{5}, \theta_{4}\right), T_{2}=\left[\theta_{4}, \bar{\theta}\right], T_{3}=\left[\theta_{6}, \theta_{5}\right)$, and $T_{4}=\left[\underline{\theta}, \theta_{6}\right)$. Note that in this case the average quality of traded durables is lower than that of nontraded durables, since $\theta_{4}>\theta_{5}$. By using the utility functions:

$$
\begin{aligned}
\theta_{4} & =\frac{-\beta P_{n}+(1+\beta) \beta P_{u}-\beta^{2} P_{s}-(1+\beta) m_{1}+m_{2}}{q_{n}\left(m_{2}\right)+\beta q_{u}\left(m_{2}\right)-(1+\beta) q_{n}\left(m_{1}\right)} \\
\theta_{5} & =\frac{P_{n}-(1+\beta) P_{u}+\beta P_{s}+m_{1}}{q_{n}\left(m_{1}\right)-q_{u}^{e}} \\
\theta_{6} & =\frac{P_{u}-\beta P_{s}}{q_{u}^{e}}
\end{aligned}
$$


Figure 2

Case 2: $U_{1}^{\prime}<U_{2}^{\prime}$

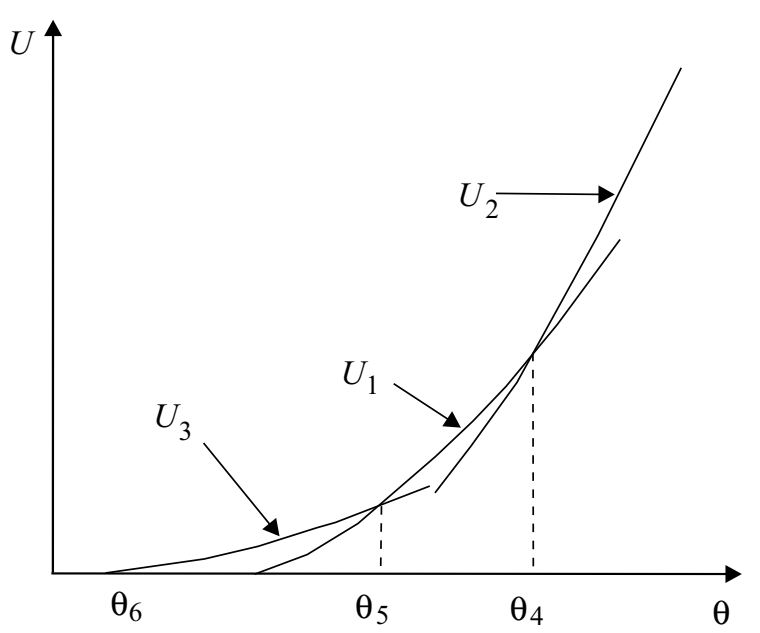

Let us briefly analyze the impact of changing the price of new durables and the scrap value. First, an increase in the price of new durables leads to the following inequalities:

$$
\begin{aligned}
\frac{\partial \theta_{4}}{\partial P_{n}} & =\frac{1}{\Delta q_{4}}\left[-\beta+(1+\beta) \beta \frac{\partial P_{u}}{\partial P_{n}}\right]<0 \\
\frac{\partial \theta_{5}}{\partial P_{n}} & =\frac{1}{\Delta q_{5}}\left[1-(1+\beta) \frac{\partial P_{u}}{\partial P_{n}}\right]>0 \\
\frac{\partial \theta_{6}}{\partial P_{n}} & =\frac{1}{\Delta q_{6}} \frac{\partial P_{u}}{\partial P_{n}}>0
\end{aligned}
$$

where $\Delta q_{4}=q_{n}\left(m_{2}\right)+\beta q_{u}\left(m_{2}\right)-(1+\beta) q_{n}\left(m_{1}\right), \Delta q_{5}=q_{n}\left(m_{1}\right)-q_{u}^{e}$ are the quality differences between two successive levels. As before, we know that $0<$ $\frac{\partial P_{u}}{\partial P_{n}}<\frac{1}{1+\beta}<1$. Therefore, as the price of new durables increases, the supply of and demand for used durables decrease. This implies a higher average quality of new durables. The change in demand for new durables which are kept for their entire life is always positive, since $\partial D_{2} / \partial P_{n}=-w\left(\theta_{4}\right) \frac{\partial \theta_{4}}{\partial P_{s}}$ and $\frac{\partial \theta_{4}}{\partial P_{n}}<0$

Now, let us investigate the case of increasing the scrap value. The marginal consumers will change as follows: 


$$
\begin{aligned}
\frac{\partial \theta_{4}}{\partial P_{s}} & =\frac{1}{\Delta q_{4}}\left[-\beta^{2}+(1+\beta) \beta \frac{\partial P_{u}}{\partial P_{s}}\right]>0 \\
\frac{\partial \theta_{5}}{\partial P_{s}} & =\frac{1}{\Delta q_{s}}\left[\beta-(1+\beta) \frac{\partial P_{u}}{\partial P_{s}}\right]<0 \\
\frac{\partial \theta_{6}}{\partial P_{s}} & =\frac{1}{\Delta q_{6}}\left[\frac{\partial P_{u}}{\partial P_{s}}-\beta\right]<0
\end{aligned}
$$

As before, we know that $\beta>\frac{\partial P_{u}}{\partial P_{s}}>\frac{\beta}{1+\beta}$. Therefore, as the scrap value increases, the supply of and demand for used durables increase. This implies a lower average quality of new durables. The change in demand for new durables which are kept for their entire life is always negative, since $\partial D_{2} / \partial P_{s}=-w\left(\theta_{4}\right) \frac{\partial \theta_{4}}{\partial P_{s}}$ and $\frac{\partial \theta_{4}}{\partial P_{s}}>0$.

Note that when one increases (decreases) the price of new durables or decreases (increases) the scrap value, it implies an increase (decrease) in the depreciation cost. Thus, the demand for and supply of used durables increases (decreases). On the other hand, the demand for durables which are kept for the lifetime increases (decreases), since the marginal consumer $\theta_{4}$ will choose option 2 (option 1 ).

\subsection{Equilibria under perfect and imperfect information}

There are some possible extensions to this model. For example, there might be an information acquisition process, so that potential buyers may know the quality of used durables. This could happen through a warranty from dealers, examination of the quality of the used durable, and so forth.

In this section, we extend the quality differentiation in the used durables market to include perfect information on the part of buyers on the quality of used durables. To do so, we make the following assumption:

ASSUMPTION 8 There are only two possible maintenance levels when durables are new: high (h) and low (l), so that $m_{n}^{h}>m_{n}^{l}$ and $q_{u}^{h} \equiv q_{u}\left(m^{h}\right)>q_{u}\left(m^{l}\right) \equiv q_{u}^{l}$. That is, the higher the maintenance level, the higher its cost, but the higher the quality of the used durable in the second period.

Therefore, consumers now face the following options: 1h) buy a new durable and maintain it at high level; 1l) buy a new durable and maintain it at low level; $2 \mathrm{~h}$ ) buy a new durable and maintain it at high level, but keep it for the entire life; 
2l) buy a new durable, but maintain it at low level; 3h) buy a high level maintained used durable quality; 31) buy a low level maintained used durable quality; and 4) use the best substitute. Note that now in this case:

$$
P_{u} \equiv P_{u}\left(m_{n}\right)
$$

i.e., the price of the used durable quality will be a function of the maintenance quality when the durable was new. Thus, two possible prices for used durables are $P_{u}^{h} \equiv P_{u}\left(m_{n}^{h}\right)$ and $P_{u}^{l} \equiv P_{u}\left(m_{n}^{l}\right)$, when the maintenance in the first period was high and low, respectively. We shall assume, without loss of generality, that there is no market for durables which are kept for their entire life at a low maintenance level, so that option 2l) is discarded.

The utility functions for a type- $\theta$ consumer are as follows:

$$
\begin{aligned}
U_{1}^{h}(\theta) & =(1+\beta)\left[-P_{n}+\beta P_{u}^{h}+\theta q_{n}^{h}-m^{h}\right] \\
U_{1}^{l}(\theta) & =(1+\beta)\left[-P_{n}+\beta P_{u}^{l}+\theta q_{n}^{l}-m^{l}\right] \\
U_{2}^{h}(\theta) & =-P_{n}+\beta^{2} P_{s}+\theta q_{n}^{h}+\beta \theta q_{u}^{h}-m^{h} \\
U_{3}^{h}(\theta) & =(1+\beta)\left[-P_{u}^{h}+\beta P_{s}+\theta q_{u}^{h}\right] \\
U_{3}^{l}(\theta) & =(1+\beta)\left[-P_{u}^{l}+\beta P_{s}+\theta q_{u}^{l}\right] \\
U_{4}^{\prime}(\theta) & =0
\end{aligned}
$$

We redefine our definition of equilibrium in the secondary market as follows:

DEFINITION 2 The secondary durable good market for a two-period durable good is in (stationary) equilibrium, given $P_{n}$ and $P_{s}$, if there exists $P_{u}$ such that:

$$
\begin{aligned}
& D_{1}^{h}=D_{3}^{h} \\
& D_{1}^{l}=D_{3}^{l}
\end{aligned}
$$

and $D_{1}^{h}$ and $D_{3}^{l}$ are the demands for options 1 and 3, respectively, when the high maintenance level is chosen in the first period and when the low maintained level is chosen in the first period.

As before, condition (3) is the market-clearing condition for the high maintenance level used durable market, and condition (4) is a similar condition for 
the low maintenance level used durable market. Likewise the case of asymmetric information, we have two cases: 1) $U_{1}^{l^{\prime}}>U_{2}^{h^{\prime}}$ and 2) $U_{2}^{h^{\prime}}>U_{1}^{l^{\prime}}$. However, in this section we are interested in comparing the cases of perfect information and imperfect information on the quality of used durables. Under imperfect information, consumers are assumed to make their decisions based on the average quality of the used durables, $q_{u}^{e}$. Thus, under imperfect information, the utility functions for a type- $\theta$ consumer are:

$$
\begin{aligned}
U_{1}^{h}(\theta) & =(1+\beta)\left[-P_{n}+\beta P_{u}^{e}+\theta q_{n}^{h}-m^{h}\right] \\
U_{1}^{l}(\theta) & =(1+\beta)\left[-P_{n}+\beta P_{u}^{e}+\theta q_{n}^{l}-m^{l}\right] \\
U_{2}^{h}(\theta) & =-P_{n}+\beta^{2} P_{s}+\theta q_{n}^{h}+\beta \theta q_{u}^{h}-m^{h} \\
U_{3}^{\prime}(\theta) & =(1+\beta)\left[-P_{u}^{e}+\beta P_{s}+\theta q_{u}^{e}\right] \\
U_{4}(\theta) & =0
\end{aligned}
$$

where $q_{u}^{e}=\left(D_{1}^{h} q_{u}^{h}+D_{1}^{l} q_{u}^{l}\right) /\left(D_{1}^{h}+D_{1}^{l}\right)$ and $P_{u}^{e}$ is determined by $D_{1}^{h}\left(P_{u}^{e}\right)+D_{1}^{l}\left(P_{u}^{e}\right)$ $=D_{3}\left(P_{u}^{e}\right)$, and $D_{3}$ is the demand for used durables. A numerical example is used to illustrate the equilibria under perfect information and imperfect information.

NUMERICAL EXAMPLE 2: We extend the previous numerical example in the last section to the case of discrete quality levels as stated in Assumption 8. We investigate the equilibria under perfect information and imperfect information for two possible cases:

Case 1:

$$
(1+\beta) q_{n}^{l}>q_{n}^{h}+\beta q_{u}^{l}
$$

Case 2:

$$
(1+\beta) q_{n}^{l}<q_{n}^{h}+\beta q_{u}^{l}
$$

The distribution of consumers preferences is given by $w(\theta)=1, \theta \in[0,10]$. In addition, we assume that $P_{n}=10, P_{s}=1, m^{l}=1, q_{u}^{h}=1.25, q_{n}^{l}=2$, and depending on the case: Case 1) $q_{n}^{h}=2.45, \beta=0.9, q_{u}^{l}=0.8$, and $m^{h}=5$ so that condition (5) holds; and Case 2) $q_{n}^{h}=2.5, \beta=0.6, q_{u}^{l}=0.935$ and $m^{h}=5.5$, so that condition (6) holds. 
Both numerical examples show that there is no market for option $2 \mathrm{~h}$ under perfect information. The gains by trading are high enough to offset the marginal gain of owning and keeping a durable good for its entire life.

Moreover, both cases show that lower preference consumers are worse off under perfect information, since they belong to a class of consumers who do not own a durable. This is because the effective price of used durables under imperfect information, $P_{u}^{e} / q_{u}^{e}$, is lower than the effective price of low-maintained used durables, $P_{u}^{l} / q_{u}^{l}$.

\subsection{A policy evaluation exercise ${ }^{6}$}

In the previous two subsections, we draw several conclusions on how exogenous factors affect the composition of durable good stocks. These results could be applied to evaluate policies for the control of the externality level associated with the use and quality of durable goods in the long-term. Thus, to analyze the impact of these regulatory programs, it is important to study the associated changes in the composition of durable stocks.

Assume that each quality level is linearly related to the externality level, and the regulator wants to minimize total externality level (e.g., emissions from automobiles). Recall Numerical Example 1 in which case (b) shows that the average quality of nontraded durables (kept for two periods by owners) is lower than the quality of traded ones.

If a regulator decides to impose a stricter emission standard, the demand for and supply of traded durables will in fact decrease. However, the demand for traded durables, $D_{2}$, will increase if $\frac{w\left(\theta_{2}\right) \Delta q_{1}}{w\left(\theta_{1}\right) \Delta q_{2}}>\beta$.

Combining the results of the last two paragraphs, we have two opposing forces: 1. The regulator imposing stricter (i.e. lower externality level) to new durables which might imply higher prices of new durables, and 2. A higher demand for nontraded durables (kept for two periods) with lower quality (e.g., higher emissions) which might offset partially the regulator willingness to decrease total externality.

This might have been the case of emissions from automobiles. The government agency has imposed stricter standards on emissions at expense new car prices. Stocks of older vehicles with lower emission standards have grown as consumers decide to keep them longer. This may have implied higher emissions from automobile, contrary to the regulator's goal.

\footnotetext{
${ }^{6}$ See chapter 4 of Saito (1994). We show how the California Air Emissions Board (CARB) policy to reduce air emissions in California by the introduction of zero-emission vehicles may turn out to increase total level of pollution rather than reducing it even in the long-term.
} 


\section{Conclusions}

This paper focused on the quality differentiation of durable goods in secondary markets. We used a description of a market for durable goods - which includes scrappers, producers, and consumers - to derive the optimal condition and thus to characterize the demand for each asset in equilibrium. We studied the characterization of the demand under two situations: 1 . The qualities for each asset are not changed by the consumer's pattern of usage; and 2. The consumer can choose the operation and/or maintenance level in the period the durable goods are new, which determines the quality levels for the subsequent periods. We study the effects of information on the quality of used durables under two circumstances: asymmetric information and perfect information.

Under asymmetric information, information plays an important role. Because the quality level is only known in the period that goods are new, consumers who buy used durables make their evaluations based on the average quality. By using a two-period durable good model, we determine the equilibrium conditions, and apply these conditions to determine how the composition of stocks of new and used durables change when either the price of new durables or the scrap value changes. Our results show that as the price of new durables (or the scrap value) increases, the supply and demand for used durables decrease. This implies a higher average quality of used durables. The change in demand for durables kept for their entire life by consumers increases, when one increases the price of new durables in the case that the marginal utility of the option of keeping the durables for the entire life is higher than the marginal utility of the option of buying new durables. For the opposite case, the change will depend on the shape of the distribution of consumers with respect to the taste for quality and the difference in quality levels.

Under perfect information, the market for durables which are kept for the entire lifetime does not exist. Numerical examples are provided to show that under perfect information, consumers will keep durables for only one period and then trade them.

We provide an example in which our comparative static results could be applied to evaluate policies for the control of the externality level associated with the use and quality of durable goods in the long-term. In this example, the regulator imposes stricter quality standards for new durables to decrease negative externality associated with the use of durables. However, comparative static results show that policies focusing only on new durable externality control may turn out to increase total externality, since stocks of older vintages with less stricter standards may increase. 


\section{References}

Berkovec, J. (1985). New car sales and used car stocks: A model of the automobile market. RAND Journal of Economics, 16(2):195-214.

Bond, E. (1983). Trade in used equipment with heterogeneous firms. Journal of Political Economy, 91(41):688-705.

Chow, G. C. (1957). Demand for automobiles in the United States: A study in consumer durables. North-Holland, Amsterdam.

Deneckere, R. \& de Palma, A. (1988). The diffusion of consumer durables in a vertically differentiated oligopoly. RAND Journal of Economics, 29(4):750-71.

Hamilton, N. \& Burke, M. (1996). The coase conjecture in continuous time: Imperfect durability, endogenous durability, and aftermarkets. John Hopkins Working Paper \# 362.

Kim, J. (1985). The market for 'lemons' reconsidered: A model of the used car market with asymmetric information. American Economic Review, 75(4):83643.

Parks, R. W. (1977). The determinants of scrapping rates for postwar vintage automobiles. Econometrica, 45:1099-15.

Purohit, D. (1992). Exploring the relationship between the markets for new and used durable goods: The case of automobiles. Marketing Science, 11(2):154-167.

Rust, J. (1985). Stationary equilibrium in a market for durable assets. Econometrica, 53(4):783-805.

Saito, R. (1994). Quality regulation of durable goods in the presence of externalities. Ph. D. Dissertation, Department of Engineering-Economic Systems, Stanford University.

Sweeney, J. L. (1974). Quality, commodity hierarchies, and housing markets. Econometrica, 42(1):147-67. 